\title{
Water Users' Perspectives: Summary of Withdrawal Survey Responses and Commentary
}

\author{
C. Alex Pellett ${ }^{1}$ and Thomas Walker III $^{2}$
}

AUTHORS: ${ }^{1}$ Hydrologist, South Carolina Department of Natural Resources, 311 Natural Resources Drive, Clemson, SC 29631. ${ }^{2}$ Postdoctoral Fellow, South Carolina Water Resources Center, 509 Westinghouse Road, Clemson University, Pendleton, SC 29670.

\begin{abstract}
The state of South Carolina is currently in a multiyear process of updating the State Water Plan, and water demand projections are an important component of that work. Predictions of water demand are inherently uncertain, but perhaps they can benefit from input by a diverse and robust sample of water users. A brief survey regarding water use was distributed to 780 permitted and registered water users in the state, including all water suppliers, industries, and irrigators withdrawing more than 3 million gallons in a month or more than 100,000 gallons in a day. There are 316 responses to 10 quantitative survey items that are summarized, presented, and discussed. Results indicate that most respondents plan to maintain their current levels of water use, consider their withdrawal reports to be accurate within 10\%, and believe their current water supplies to be critical to their enterprise. A qualitative review of comments noted on survey responses includes a variety of potential drivers of water demand. The results motivate a discussion of recommendations for future research.
\end{abstract}

\section{INTRODUCTION}

The purpose of this article is to describe trends that could be relevant for projecting future water demand. The costs of collecting detailed information on water use across the state can be substantial, and the time required to do so could render some information obsolete by the time the data collection process is considered complete. In this context, a short survey was devised and disseminated among permitted and registered water users in the state as a lowcost and efficient method to gain insight into current and future water demand. Quantitative and qualitative survey responses are summarized by use category, indicating trends in water demand, withdrawal reporting, and potential factors affecting future water use. Understanding current water use trends will inform estimation of future water demands, a key part of planning for water availability.

The specific objectives of this work are to (a) determine how water users' plans will impact their future water use, (b) investigate the accuracy with which water withdrawal data is reported, (c) assess the importance of current water supplies to water users' enterprises, and (d) compile a list of potential factors which could affect future water use in South Carolina.

In this report, water use is meant to include the withdrawal of fresh water from the environment and subsequent distribution of the water according to the socioeconomic motivations of humanity. In-stream uses such as hydropower and fishery habitat, though important, are not considered within the scope of this report.

\section{BACKGROUND}

Mail and phone surveys have long been used to collect water use information (Holland, 1992). Although online water use reporting tools have also been used in some cases, mailed or downloaded forms and mail surveys continue to be available for water use reporting (Texas Water Development Board, 2017; South Carolina Department of Health and Environmental Control [SCDHEC], 2012).

As water planning in South Carolina has proceeded, many stakeholders have provided information regarding their use of and appreciation for the state's water resources. Water users who withdraw $\geq 100,000$ gallons of water are required to obtain a permit or registration from SCDHEC. The mandatory permitting requirement came into effect July 1, 1983. Harrigan (1985) sought out reports of water volume and achieved an overall response rate of $67 \%$ after repeated mailings (Table 1).

The goal of the 1985 survey was to collect water usage information from all users believed to have a maximum single-day water usage $\geq 100,000$ gallons. Power plants had a $96 \%$ response rate in the first mailing, and they are by far the largest water users in terms of volume. Excluding power 
Table 1. 1983 Voluntary survey response rate of water users in South Carolina (Harrigan, 1985).

\begin{tabular}{lcccc}
\hline & & \multicolumn{3}{c}{ Responses } \\
\cline { 3 - 4 } & & \multicolumn{2}{c}{ Mailing } & Overall \\
\cline { 3 - 4 } Category & Sent & First & Second & Rate \\
Public Supply & 268 & 101 & 81 & $68 \%$ \\
Industry & 432 & 346 & 55 & $93 \%$ \\
Agriculture & 681 & 269 & 126 & $58 \%$ \\
Power & 52 & 50 & 2 & $100 \%$ \\
Golf Courses & 180 & - & 51 & $28 \%$ \\
\hline
\end{tabular}

plants, the 716 respondents to the first 1,381 surveys (golf courses were not included in the first mailing) represented about $75 \%$ of the remaining withdrawal water usage (Harrigan, 1985).

The second mailing of forms was put together with cover letters customized to different groups of nonrespondents based on likely reasons for not responding. Water use reporting provided official documentation of water use that could be used in case of conflicting demands. The South Carolina Water Resources Commission would use this information to identify water-deficient areas. Roughly a third of users who were obligated to report had already done so elsewhere, and duplicate reports were not required (Harrigan, 1985).

Following recommendations in water planning documents (Castro \& Hu, 1997), reporting monthly water withdrawal volume became a mandatory annual ritual that now achieves a $>99 \%$ overall response rate every year.

When the survey for the present study was distributed in 2017, there were 780 permitted and registered water users in the state. This population varies from farmers irrigating $<100$ acres to large power-generation projects including combustion and nuclear-powered thermoelectric generators operating in tandem with hydroelectric generators in multiple reservoirs. These various users are united in their reliance on a sufficient quantity of water to sustain their enterprise and dependent populations. The water users' contribution of time and effort in monitoring and reporting their monthly water withdrawal has enabled the compilation of a long-term dataset which can provide information on historic conditions and insight into current water use patterns. But to forecast future trends in water use, greater perspective is needed to provide context. Current water use patterns are less relevant if practices are expected to change in the future. If water withdrawers in South Carolina respond well to voluntary surveys, as demonstrated by Harrigan in 1985, then a similar survey could provide information with which to guide efforts to project future water demand.

\section{METHODS}

The survey was composed of 20 items, including 3 used for identification purposes and 1 for follow-up email correspondence. The survey forms were attached to a cover letter describing the optional survey and with instructions on how to complete it (see Appendix for survey form and cover letter). A uniform survey and cover letter were prepared for all water users, with some specific instructions for irrigators and water suppliers.

The survey tool used to gather the quantitative and qualitative data for this research used a mailing survey, which was desirable for this research for several reasons. One benefit is the ease of distribution using a mailer that was already being sent to all registered or permitted users. Another benefit is that it was less duplicative and likely increased response rates. Additionally, some water users do not access the Internet, so using a digital-only survey would be exclusive. Digital survey tools, although not as desirable for this round of surveys, might be developed in subsequent years along with paper copies for mailing surveys.

The survey and attached cover letter were mailed by SCDHEC with the annual water withdrawal reporting forms to all registered and permitted users in the state. Envelopes were mailed the first week of December 2017, and followup envelopes were sent mid-February to permitted and registered water users who had not responded to the annual water withdrawal reporting forms.

\section{RESULTS}

Results of this survey are presented corresponding to each of the 4 specific goals of the project. Results are divided between quantitative and qualitative summaries of survey responses and are presented for each category of water use. Response rates vary between survey items; not all respondents replied to all survey items, and some respondents marked multiple answers to some survey items.

\section{QUANTITATIVE SUMMARY}

Table 2 summarizes the number of responses from each category of water withdrawers. Table 3 summarizes respondents' plans regarding the volume of water withdrawn at their enterprise over the next 5 years. Mining operations were most likely to expect an increase in their water withdrawals over the next 5 years. Water suppliers were the next most likely to expect an increase in their withdrawals. The majority of golf courses are expected to maintain current levels of withdrawal. Most agricultural and industrial withdrawals are also expected to maintain current volumes, but many expect to increase, and fewer expect to decrease. Table 4 summarizes responses on a similar topic, this time regarding the source of water over the next 5 years. 
Table 2. 2017 Voluntary survey response rate of water users in South Carolina.

\begin{tabular}{lccc}
\hline Category & Sent & Responses & Rate \\
\hline Agriculture & 327 & 159 & $49 \%$ \\
Golf Course & 157 & 59 & $38 \%$ \\
Industry & 83 & 33 & $40 \%$ \\
Mining & 14 & 7 & $50 \%$ \\
Thermoelectric & 17 & 17 & $100 \%$ \\
Water Supply & 190 & 58 & $31 \%$ \\
\hline
\end{tabular}

Table 3. Water users' 5-year plans regarding withdrawal volume.

\begin{tabular}{lcccc}
\hline Category & Increase & Maintain & Decrease & Don't Know \\
\hline Agriculture & 47 & 72 & 5 & 34 \\
Golf Course & 5 & 40 & 6 & 11 \\
Industry & 6 & 18 & 4 & 5 \\
Mining & 6 & 1 & 0 & 0 \\
Water & 33 & 15 & 1 & 10 \\
Supply & & & & \\
\hline
\end{tabular}

Table 4. Water users' 5-year plans regarding water source.

\begin{tabular}{lccccc}
\hline Category & $\begin{array}{c}\text { More } \\
\text { Surface }\end{array}$ & $\begin{array}{c}\text { More } \\
\text { Ground }\end{array}$ & $\begin{array}{c}\text { More } \\
\text { Purchased }\end{array}$ & Maintain & $\begin{array}{c}\text { Don't } \\
\text { Know }\end{array}$ \\
\hline $\begin{array}{l}\text { Agricul- } \\
\text { ture }\end{array}$ & 8 & 42 & 1 & 81 & 31 \\
$\begin{array}{l}\text { Golf } \\
\text { Course }\end{array}$ & 3 & 3 & 0 & 46 & 7 \\
Industry & 4 & 2 & 2 & 21 & 6 \\
Mining & 2 & 4 & 0 & 1 & 0 \\
$\begin{array}{l}\text { Water } \\
\text { Supply }\end{array}$ & 11 & 26 & 3 & 12 & 7 \\
\hline
\end{tabular}

Table 5. Number of respondents using different calculation methods by category of water use.

\begin{tabular}{lcccc}
\hline Category & $\begin{array}{c}\text { Flow } \\
\text { Meter }\end{array}$ & $\begin{array}{c}\text { Pumping } \\
\text { Time }\end{array}$ & $\begin{array}{c}\text { Pumping } \\
\text { Energy }\end{array}$ & $\begin{array}{c}\text { Estimation/ } \\
\text { Reckoning }\end{array}$ \\
\hline Agriculture & 21 & 109 & 10 & 20 \\
Golf Course & 44 & 18 & 1 & 0 \\
Industry & 25 & 8 & 1 & 2 \\
Mining & 0 & 7 & 0 & 0 \\
Water Supply & 56 & 5 & 0 & 0 \\
\hline
\end{tabular}

Table 6. Responses estimating the precision of reported withdrawals by the various methods used to calculate withdrawal volume.

\begin{tabular}{lcccc}
\hline $\begin{array}{l}\text { Estimated } \\
\text { Precision }\end{array}$ & $\begin{array}{c}\text { Flow } \\
\text { Meter }\end{array}$ & $\begin{array}{c}\text { Pumping } \\
\text { Time }\end{array}$ & $\begin{array}{c}\text { Pumping } \\
\text { Energy }\end{array}$ & $\begin{array}{c}\text { Estimation/ } \\
\text { Reckoning }\end{array}$ \\
\hline Exact & 67 & 17 & 1 & 2 \\
$\leq 10 \%$ & 72 & 90 & 4 & 12 \\
$\leq 20 \%$ & 3 & 36 & 6 & 2 \\
$>20 \%$ & 1 & 4 & 1 & 6 \\
\hline
\end{tabular}

Figure 1 indicates that the perceived precision of water use reports varies among users and between different categories of use. As shown in Table 5, respondents in different categories tend to rely on different methods with which to calculate their monthly withdrawal volume. Table 6 compares the methods of calculation with the perceived precision of the reported volume; respondents tended to expressed high confidence in reported volume estimates derived from flow meters.

Figure 2 shows that most of the responding water users' enterprises are critically reliant on their current water supplies-their enterprises would cease without adequate water availability. Nevertheless, most respondents are not very concerned about future water availability for their enterprise (Figure 3). Notably, 100\% of respondents representing mining enterprises described their operations

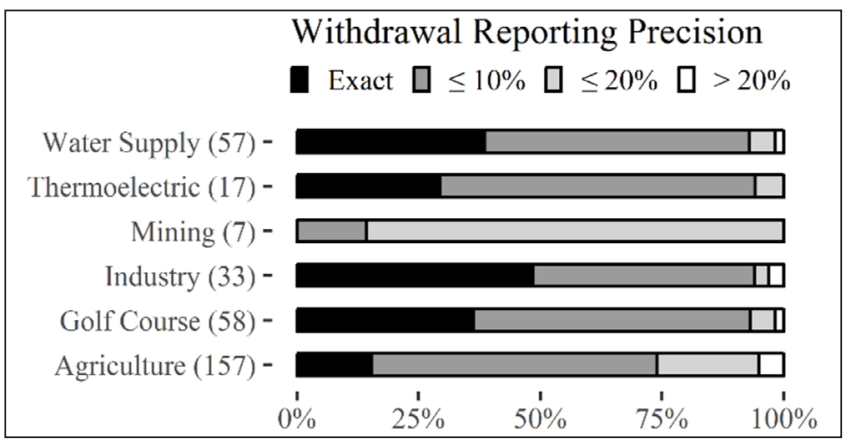

Figure 1. Water users' estimated reporting precision by category of use.

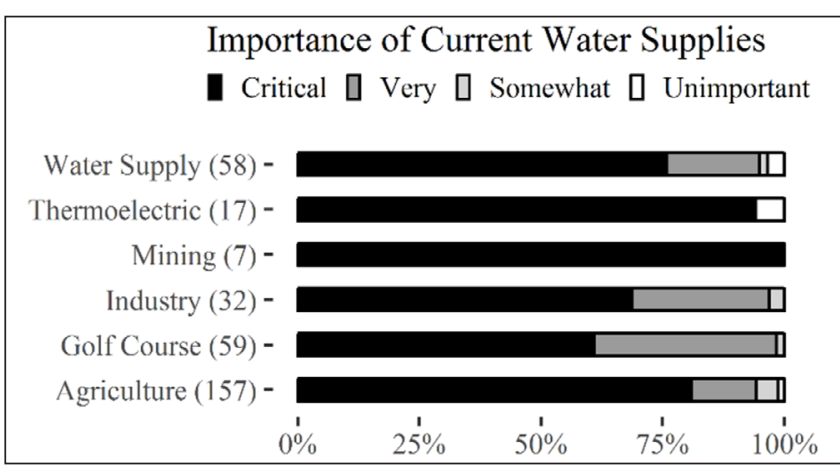

Figure 2. The importance of current water supplies to the continuation of water using enterprises summarized by category.

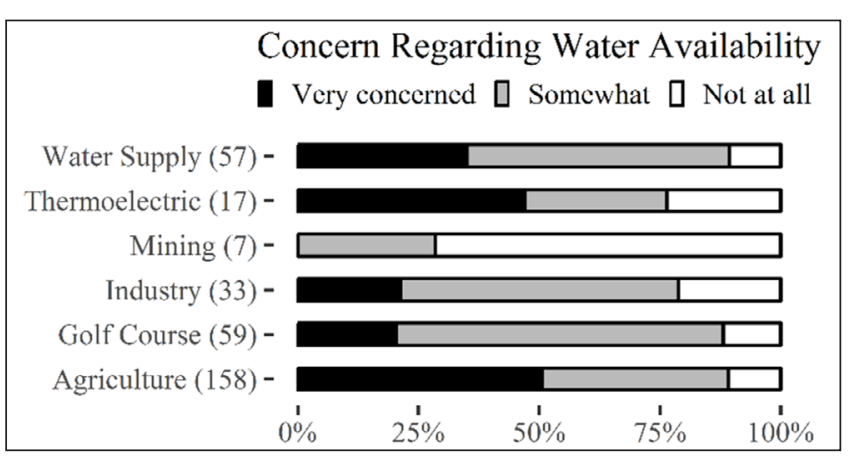

Figure 3. Water users' level of concern regarding the availability of their water supplies in the future, summarized by category. 
as critically reliant on their water supplies, but none were very concerned regarding future availability, and most were not at all concerned about a shortage.

Finally, Table 7 summarizes some additional information that came from the survey responses. Some users are aware of existing studies that project water use at their enterprise. Respondents answered whether they purchase water in addition to their withdrawal volume and whether they sell water wholesale to water distributors.

Table 7. Additional information in the survey responses.

\begin{tabular}{lcccc}
\hline Category & Existing Studies & Purchase & Wholesale & Reuse \\
\hline Agriculture & 10 & 12 & 0 & 19 \\
Golf Course & 7 & 3 & 0 & 12 \\
Industry & 5 & 24 & 1 & 21 \\
Mining & 0 & 0 & 0 & 6 \\
Water & 9 & 12 & 20 & 7 \\
Supply & & & & \\
\hline
\end{tabular}

Industries, thermoelectric power plants, golf courses, water suppliers, and agricultural irrigators indicated that some amount of reclaimed or recycled water was used in their enterprises. The survey item did not distinguish between on-site reuse of water within an enterprise and reclamation of water discharged from another enterprise, although comments indicate that both kinds of water reuse occur in South Carolina.

\section{QUALITATIVE SUMMARY}

The survey included 2 open-ended questions designed to elicit responses listing potential factors or trends that could impact water use in the future. Factors relating to the enterprises' economic markets and relevant developments in technology were sought. About half of respondents left these items blank or responded with something to the effect of "none," "do not know," or "not applicable." The remaining responses are summarized here for each category of water use.

Agriculture. Of the agricultural water users who responded to this question, the most common responses regarded commodity price fluctuations. If corn prices rise, then more corn will be planted, and corn requires relatively higher levels of irrigation. Some comments indicated that when commodity prices are low, irrigation becomes more important; other comments seemed to contradict that viewrespondents indicated that commodity prices could be so low that the costs of operating irrigation equipment might not be offset by the increased yield. Corn was the most commonly used example in the responses, but other crops mentioned include pine, hay, sorghum, and sod. Among sod producers, increasing consumer demand for drought-tolerant varieties was a market factor that is expected to decrease their water demand. However, it was also noted that an increase in housing development would increase total demand for sod (and other landscaping plants), which could increase the water demand of producers.

Many respondents noted, in response to these questions or in comments in the margins of other questions, that their water use is dependent on weather. The relationship between irrigation and weather is well established and could even be considered an a priori assumption in water demand forecasting. Other notable responses included an increasing demand for locally grown produce, developments in the North American Free Trade Agreement, and solar panel lease agreements.

Technological advances that commenters believed could impact their water use include new drought-resistant crop varieties, variable-rate irrigation allowing different irrigation depths on different soil types within the same field, moisture probes or sensors, drip irrigation, row covers, no-till or striptill combined with cover crops, drip nozzles, unmanned aerial vehicles (i.e., drones) providing an overhead perspective on crop condition, and GPS-enabled irrigation equipment.

Golf courses. Among respondents representing golf course irrigation, several comments regarded changing perspectives on how golf courses should be maintained: Respondents noted the desire among some players for "firm and fast conditions," as well as a growing acceptance of "brown is the new green" and allowing for more natural vegetation in outof-play areas of the course. These 3 trends in the golf course market allow for decreased irrigation; they also tend to make play more challenging.

Technological factors that were noted include the development and application of enhanced "wetting agents"; more drought-tolerant turf varieties; and sensors, irrigation sprayers, and digital control systems that allow for more precise application of irrigation.

Mining and industry. Respondents representing mining and industrial water withdrawals commonly cited market demand for their product as a leading factor in water use at their facility. Customer demand for environmentally friendly products, technological improvements in process efficiency, reverse osmosis technology, and changing regulations were also noted.

Thermoelectric power. Some of the comments in the responses indicated that power utilities have significant confidence in their predictions of future water use. Power utilities withdraw, by far, the most water of any other water use category (DHEC, 2015). Interconnections in the power grid extend across the continent, buffering individual power plants from variations in local demand. Upgrades, 


\section{Water Users' Perspectives}

renovations, or closures are generally the result of years of planning.

Water supply. Water suppliers commonly cited increased development of residential housing and commercial and industrial sector growth as drivers of water use. Some suppliers provide water to bottling plants, and growth in the market for bottled water is expected to continue. Factors that various suppliers mentioned that could decrease their consumptive withdrawals included state and federal regulations (including the progression of regulations allowing for aquifer recharge using treated wastewater), more efficient fixtures and building codes that mandate their use, water rate increases, increased industrial water reuse, reverse osmosis water treatment technology, leak-detection equipment, rainwater collection, automatic meter reading and advanced metering infrastructure (better ensuring accurate metering), and water for outdoor irrigation withdrawn directly from lakes by lakefront property owners .

\section{DISCUSSION}

This project is an example of effective collaboration between South Carolina Department of Natural Resources, SCDHEC, and the permitted and registered water withdrawers in the state for the common goal of water resource management. The responses represent a goodfaith effort by the various communities of water users in the state to provide valuable feedback for water planning. The project has achieved the specific goals introduced here, and it has done so at a very low cost to the state. Based on the results compiled in this effort, certain critiques can be made regarding the survey items and the interpretability of responses. Survey items about reporting accuracy, concerns about water availability, water reuse and reclamation, and qualitative responses are discussed further.

Reporting accuracy. The results indicate that reporting accuracy and precision varies between withdrawal categories and between methods of calculating withdrawal volume. In addition to the respondents' perceived accuracy, digitization of their handwritten withdrawal reports on the mandatory reporting forms can introduce additional error and uncertainty.

Concerns about water availability. The survey item regarding concerns about water availability (Figure 3) does not distinguish between physical and legal availability. Many withdrawers are not concerned about either, but for those who expressed concern, it is unclear whether their concern is based on the possibility of a drought or a groundwater decline causing a shortage or if the concern is more related to perceived uncertainty in the water users' legal right to use their water supply.

Water reuse and reclamation. The survey item regarding water reuse and recycling was ambiguous and could be improved. On-site reuse is a water conservation practice that reduces both total withdrawal and total discharge for a given enterprise. In the context of water demand modeling, on-site reuse can be considered equivalent to other water conservation measures.

Reclamation of discharges, on the other hand, reduces the return flows from the contributing enterprise (the discharger) and helps to satisfy the water demands of the receiving enterprise. This practice can reduce total withdrawal, and it can also improve water quality if pollutants in the wastewater are diverted from environmental water bodies. In the context of water demand modeling, reclamation of discharges from one enterprise to another can be considered more akin to water distribution than water conservation. It was noted in response comments that reclaimed wastewater supplies can be impinged by water conservation at the contributing enterprise. In Texas, wastewater return flows are allocated similarly to other sources of water, and conservation efforts that could reduce return flows are subject to regulatory review to prevent or mitigate downstream shortages.

Qualitative responses. The responses described in the qualitative summary can be interpreted as a partial list of factors potentially affecting withdrawals in the different sectors. The relative importance of these different factors is subject to interpretation. These results can serve as a starting point for further investigation of technological and economic trends affecting water use in South Carolina. These responses are not expected to compose an exhaustive and definitive list, but rather a compilation of informed opinions.

\section{RECOMMENDATIONS FOR FUTURE WORK}

The data collected in this work also allows for an analysis of water use specific to each withdrawal. The detailed responses will be used to calibrate models of water use based on the number of residential, commercial, or industrial taps (for water suppliers) and the acreage irrigated and crops planted (for agricultural and golf course withdrawals). The detailed responses from this survey will enable enterpriselevel water use models that may be used for projecting future water demand.

The surveys could be improved by addressing the ambiguities discussed in the previous section. The survey forms could also be customized for each category of withdrawal. Although the survey could easily be repeated at a minimal cost next year, that could lead to a decline in the response rate, because water users' may not be motivated to 
respond to additional paperwork every year. Alternatively, a similar survey could be repeated in 2-5 years to monitor water users' changing perspectives over time. The response rate might be improved by offering an incentive such as a raffle for a free T-shirt or a subscription to South Carolina Wildlife magazine.

\section{LITERATURE CITED}

Castro JE, Hu J. 1997. Distribution and rate of water use in South Carolina, 1994 (Hydrology-Water Resources Report 18). Columbia (SC): South Carolina Department of Natural Resources.

Harrigan JA. 1985. Water use in South Carolina, July-December, 1983 (Hydrology-Water Resources Commission Report 148). Columbia (SC): South Carolina Department of Natural Resources.

Holland TW. 1992. Water-use collection techniques in the Southeastern United States, Puerto Rico, and the U.S. Virgin Islands. (Water-Resources Investigations Report 92-4028). Little Rock (AR): U.S. Department of the Interior.

South Carolina Department of Health and Environmental Control (SCDHEC). 2012. R.61-119, Surface water withdrawal, permitting, and reporting. Columbia (SC): Author. South Carolina Department of Health and Environmental Control (SCDHEC). 2017. 2015 Reported water use: South Carolina. Columbia (SC): Water Quantity Permitting Section, Division of Water Monitoring, Assessment, and Protection, Bureau of Water. https://www.scdhec.gov/sites/default/files/docs/ Environment/docs/WaterQualityStandards/2015\%20 Reported\%20Water\%20Use.pdf.

Texas Water Development Board. 2017. Required survey of ground and surface water use for the calendar year ending December 31, 2017. Austin (TX): Author. https://www. twdb.texas.gov/waterplanning/waterusesurvey/survey/ doc/2017/2017 Coverletter.pdf. 


\section{APPENDIX: \\ Cover Letter and Water Use Survey}

\section{South Carolina Department of Natural Resources}

Greetings permitted or registered water withdrawer:

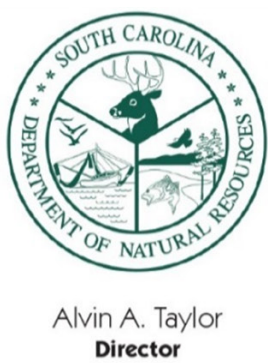

Ken Rentiers Deputy Director for Land, Water and Conservation

First and foremost, we would like to thank you for your compliance with South Carolina's water use permitting, registration, and reporting regulations. The information you provide is crucial to ensure adequate management of our State's water resources.

Our State is blessed with an abundance of water resources, to the benefit of many diverse stakeholders. However, intense and unpredictable weather extremes pose significant hazard, and our growing population and economy can increase our need for clean and reliable water supplies. Furthermore, we must plan and protect our water resource interests to mitigate potential conflicts within South Carolina and across state lines.

The South Carolina Department of Natural Resources has initiated a multi-year effort to develop Regional Water Plans for the State. Water demand forecasts can help all stakeholders and water users plan effectively. We recognize that water users have valuable insights from firsthand experience using water to meet their needs. We ask for your assistance in providing accurate data to improve our water demand forecast for your enterprise.

The attached survey includes 20 questions regarding water use at your enterprise. The questions are designed to get your input on the importance of your water sources, to understand the accuracy of reported water withdrawals, and to better understand how water is used at your enterprise. By participating in this survey, you can help ensure that the needs and interests of your organization are represented accurately in your basin's Regional Water Plan. Your response to this survey is optional and voluntary. Responses will be compiled and combined with other datasets to develop water demand models for public supply, irrigation, energy utilities and industry. These models will be reviewed by technical advisory committees and made available for review by the general public.

For FARMERS: Clemson will be conducting a more detailed and thorough survey in the Spring of 2018. If you provide your Registration ID in this survey, then your responses be shared with investigators at Clemson so that our data collection efforts are as efficient as possible.

For MUNICIPAL OR RURAL SUPPLIERS: We kindly request a digital map, shapefile, or geodatabase of your service area. If you sell water to other distributors, details regarding sales volume could significantly improve our water demand modelling results.

Rembert C. Dennis Building • 1000 Assembly St • P.O. Box 167 • Columbia, S.C. 29202 


\section{Instructions for responding to the survey}

Questions 1-3 connect your survey responses to the other information we have regarding water use at your enterprise. The Permit/Registration ID code refers to the User ID on your Water Withdrawal Permit or Registration. The ID\# is two numeric digits followed by two letters followed by three numeric digits (for example: 02WS045).

Questions 4-13 are multiple choice. We hope they are self-explanatory and easily answered. Questions 14 and 15 are to better understand your enterprise's water budget. Gathering data to estimate a detailed water budget can be costly and time consuming, but even a rough estimate could be informative.

Question 16 is for water suppliers. Although we do have some relevant information from withdrawal and distribution permits, some of that information is incomplete or out of date. Sales from one water supplier to another are particularly relevant for developing models of water demand.

Question 17 is designed for irrigators and water suppliers, but it can be used by any enterprise which keeps records of how monthly water withdrawal volume is used. The examples below illustrate how to use the table to describe water use at your enterprise:

Example 1. Agricultural Irrigation

\begin{tabular}{|l|l|r|c|c|c|c|c|c|}
\hline Year & \multicolumn{1}{|c|}{ Account / Crop } & Taps / Acres & Jan & Feb & Mar & Apr & May & Jun \\
\hline 2016 & Corn & 675 & - & - & 0.9 & 2.7 & 5.5 & 7.3 \\
\hline 2016 & Soybeans & 800 & - & - & - & 2.2 & 4.3 & 6.5 \\
\hline 2017 & Corn & 800 & - & - & 1.1 & 3.3 & 6.5 & 8.7 \\
\hline 2017 & Soybeans & 675 & - & - & - & 1.8 & 3.7 & 5.5 \\
\hline
\end{tabular}

Example 2. Municipal Water Supplier

\begin{tabular}{|l|l|r|r|r|r|r|r|c|}
\hline Year & \multicolumn{1}{|c|}{ Account / Crop } & Taps / Acres & Jan & Feb & Mar & Apr & May & Jun \\
\hline 2016 & Residential & 12,096 & 6.4 & 5 & 5.5 & 6.6 & 6.6 & 7.2 \\
\hline 2016 & Commercial & 1,113 & 0.2 & 0.2 & 0.2 & 0.2 & 0.3 & 0.3 \\
\hline 2016 & Wholesale & 1 & 2.1 & 2.0 & 2.1 & 2.7 & 2.9 & 3.0 \\
\hline 2017 & Residential & 12,124 & 4.7 & 4.9 & 5.2 & 7.4 & 6.3 & 8.1 \\
\hline
\end{tabular}

These examples use million gallons per month to fill in the table, as is required by DHEC for water withdrawal reporting. If you prefer to use another unit of measurement in your survey response, please note what unit you are using in the margin of the table. Information for a single year will be helpful in understanding current baseline water use. Information for multiple years will be helpful in developing statistical forecasts of future water use.

Questions 18 and 19 are open ended, and are intended to direct our research efforts to understand current developments and trends in water use in our State. Question 20 provides you with an opportunity to stay involved with water demand forecasting efforts. You can find more information and sign up for announcements at www. scwatermodels.com

Thank you in advance for your assistance with this study. If you have any questions, comments, or concerns regarding this survey or the water demand forecasts, please feel free to contact Alex Pellett using the contact information below. Please return survey responses to DHEC with your water withdrawal reporting form.

C. Alex Pellett

Hydrologist, SCDNR

Fax: (864) 654-9168

Phone: (864) 986-6255

Email: PellettC@dnr.sc.gov 


\section{Contact name}

2. Enterprise name

3. Permit/Registration ID\#

4. How important are your current water supplies for your enterprise?

- Critical - without current sources, enterprise would cease.

- Very important - could obtain water from other sources, at significant cost.

- Somewhat important - contingency plans minimize costs during a shortage

- Not important - enterprise does not rely on current water supplies

5. Are you concerned about future water availability for your enterprise?

- Not at all concerned

o Somewhat concerned

- Slightly concerned

- Very concerned

6. How precisely do you report monthly water withdrawals?

- Exactly correct

- Within $10 \%$

- Within $20 \%$

- Greater than $20 \%$ uncertainty

7. How do you calculate monthly water withdrawals?

○ Flow meter

- Based on time pumping

- Based on energy spent pumping

o Best estimation/reckoning

o Other:

8. Over the next 5 years, I plan to:

- Increase water withdrawals

- Decrease water withdrawals

- Maintain the same volume of withdrawal

o Do not know
9. Over the next 5 years, I plan to:

- Use more surface water

- Use more groundwater

- Use more purchased water

- Maintain the current level of withdrawals

- Do not know

10. What factors will impact your water use in the future?

- Production practices reducing withdrawal

- Capital investments reducing withdrawal

- Production practices increasing withdrawal

- Capital investments increasing withdrawal

11. Are there any existing studies that forecast water demand for your enterprise?

o Yes

○ No

○ Do not know

12. Does your enterprise purchase water?
○ Yes
○ No

13. Does your enterprise practice water re-use or use reclaimed or treated wastewater?
o Yes
○ No
- Do not know

14. What percent of water used at your enterprise is returned to groundwater?

15. What percent of water used at your enterprise is returned to a river, stream, lake, or pond?

16. Do you sell water to other water distributors? If so, to whom? 
17. Please describe water use at your enterprise using the table below:

\begin{tabular}{|l|l|l|l|l|l|l|l|l|l|l|l|l|l|l|}
\hline Year & Account / Crop & Taps / Acres & Jan & Feb & Mar & Apr & May & Jun & Jul & Aug & Sep & Oct & Nov & Dec \\
\hline
\end{tabular}

18. What technological developments do you believe will impact your water use in the future?

19. What market trends do you believe will impact your water use in the future?

20. Would you like to be included in email updates regarding this survey and other water forecasting efforts? If so, please include your email address below.

\section{PLEASE RETURN SURVEY RESPONSES TO DHEC WITH WATER WITHDRAWAL REPORTING FORMS}

